\title{
Processos de Definição dos Riscos no Licenciamento Ambiental do OSX-Estaleiro/SC: uma perspectiva das comunidades envolvidas
}

\section{Risk's Definition Process of OSX-Estaleiro/SC Environmental Licensing: an involved community's perspective}

\author{
Rogério Silva Portanova \\ Universidade Federal de Santa Catarina, Florianópolis - SC, Brasil
}

\section{Luiza Landerdahl Christmann}

Centro Universitário Católica de Santa Catarina em Jaraguá do Sul, Jaraguá do Sul - SC, Brasil

\begin{abstract}
Resumo: Neste artigo buscou-se compreender o processo de definição dos riscos por parte das comunidades envolvidas no contexto do licenciamento ambiental do OSX-Estaleiro/SC, entre 2009 e 2010, no Município de Biguaçu. Utilizou-se como metodologia a abordagem qualitativa e como técnicas de pesquisa a pesquisa bibliográfica, a entrevista semiestruturada e a pesquisa documental. A teoria da sociedade de risco (BECK, 2010) foi o referencial teórico. Identificou-se a relação entre as condições materiais de vida e as percepções a respeito dos efeitos do empreendimento. Concluiu-se pela necessidade da existência de direitos sociais básicos para um processo de construção social do risco que seja legítimo e independente.
\end{abstract}

Palavras-chave: Definição dos Riscos. Licenciamento Ambiental do OSX-Estaleiro/SC. Perspectiva das Comunidades Envolvidas.
Abstract: It intended to comprehend the risk's definition process by involved community in the context of OSX-Estaleiro/SC environmental licensing, at Biguaçu, between 2009 and 2010. The qualitative research approach was adopted. The bibliographical and documental research technique was used conjunctionally with semistructured interview technique. It was adopted Ulrich Beck's risk society theory as the main theoretical reference. About results, it was realized the existence of life's material conditions and communities' effects perceptions relation. It concluded about the necessity of social basic rights for an independent and legitimate risk's social construction process.

Keywords: Public Participation. Risk's Definition. OSX-Estaleiro/SC. Environmental Licensing. Involved Community's Perspective.

Recebido em: 24/04/2014

Revisado em: 20/03/2015

Aprovado em: 22/05/2015 


\section{Introdução}

O presente artigo ${ }^{1}$ tem como objetivo compreender os elementos relacionados com o processo de definição dos riscos pela população envolvida, no contexto do licenciamento ambiental do OSX-Estaleiro/SC, ocorrido entre 2009 e 2010, com sede no Município de Biguaçu. Para isso, primeiramente, procurar-se-á realizar um retrato crítico da emergente sociedade de risco, utilizando-se, para tal, da nova noção de justiça ambiental, a fim de adequadamente apresentar o contexto contraditório em que se inserem os processos de definição de riscos socioambientais na atualidade brasileira. Desse modo, pretende-se fornecer bases teóricas para a compreensão dos fatores presentes na situação concreta, identificados por meio de entrevista semiestruturada, cujos resultados foram interpretados tendo como base metodológica a abordagem qualitativa, orientada pela perspectiva hermenêutico-dialética (MINAYO, 2008), complementada pela pesquisa documental.

A seguir, passar-se-á a apresentar os principais elementos definidores do caso concreto objeto de estudo para, em seguida, destacar os resultados da entrevista semiestruturada representados relacionados com a categoria Construindo as definições dos riscos: os efeitos do empreendimento. Então, por fim, dialeticamente, relacionar-se-ão as bases teóricas com os dados da pesquisa empírica com a finalidade de destacar as dificuldades existentes no processo de definição do risco socioambiental por comunidades carentes em direitos sociais básicos e, portanto, a existência de sérios entraves para a consolidação da participação popular em processos de tomada de decisão de gestão do risco ambiental.

\footnotetext{
1 As reflexões apresentadas neste artigo têm como base a pesquisa bibliográfica e empírica realizada no âmbito de dissertação de mestrado em Direito, constituindo-se em recorte da mencionada dissertação. Ressalta-se que a pesquisa em questão passou por avaliação do Comitê de Ética em Pesquisa da Universidade Federal de Santa Catarina, de modo que os sujeitos entrevistados assinaram Termo de Consentimento Livre e Esclarecido e o sigilo de suas identidades foi preservado.
} 


\section{Sociedade de Risco, Construção Social do Risco e Justiça am- biental: reflexões em torno do contexto socioambiental das to- madas de decisão}

As discussões sobre a crise ambiental emergiram com grande destaque na segunda metade do século XX, diante da evidência de efeitos relacionados com a poluição da água, do ar e do solo. Entende-se, portanto, que a complexidade desta temática precisará ser alvo de medidas estatais e internacionais neste início de século XXI caso tenha-se a intenção de evitar sérias consequências para a natureza e o ser humano no planeta Terra.

Nesse contexto, ressalta-se os dilemas resultantes do propósito visado por tais medidas: a busca da satisfação das necessidades essenciais de um número cada vez maior de seres humanos em consonância com a preservação do equilíbrio biológico, físico e químico natural. Diante disso, aspecto essencial a ser considerado no objetivo complexo, alvo de tais medidas, são o planejamento e a gestão da utilização de recursos naturais, para a manutenção do equilíbrio dinâmico do meio ambiente em seu conjunto, como momentos práticos em que esse difícil escopo precisa ser alvo de decisões.

Logo, dentre outras decisões de âmbito nacional a serem tomadas - como, por exemplo, a educação ambiental realizada para a transformação de valores e hábitos e a fiscalização e a punição de atos ilegais e/ou crimes ambientais - as deliberações a respeito do licenciamento de empreendimentos que utilizam recursos naturais direta ou indiretamente são aspecto central deste objetivo. No cenário dessas medidas, a necessidade de repensar a relação do ser humano com a natureza que a transforma em coisa a ser dominada e aproveitada adquire destaque frente à passagem da sociedade moderna (industrial) para uma nova realidade em emergência, que melhor permite interpretar os processos de reconhecimento do problema ambiental na atualidade: a sociedade de risco. Nesse sentido, é necessário compreender essa nova realidade do problema socioambiental que impõe tal reformulação das formas de planejar e gerir o uso de recursos naturais (e humanos). 
A teoria da sociedade de risco, de Ulrich Beck (2010), insere-se no contexto das proposições teóricas que procuram explicar as modificações ocorridas principalmente a partir da segunda metade do século XX, algumas delas denominando esse novo processo de pós-modernidade. Nesse âmbito, tem-se que a proposta de Beck não compreende tais transformações como uma superação do período da Modernidade (como o prefixo "pós" faz entender). Diferentemente, Beck entende-as como uma intensificação desse processo, como uma segunda fase de um processo de modernização mais amplo.

Nesse sentido, a segunda modernidade desenrola-se pela expansão do método científico, basicamente da dúvida metódica, sobre as próprias bases da ciência. Para além da cientificização simples, em que a dúvida metódica é colocada sobre o externo e preexistente à ciência (a natureza, o homem, a sociedade), nessa segunda gênese civilizatória, a ciência se torna objeto de questionamento: trata-se do que Beck nomeia como cientificização reflexiva. Dessa maneira, segundo Costa (2004, p. 3),

[...] se a era moderna nasce sob a marca da crítica à tradição, continuação da modernização implica a crítica à própria modernidade, conforme tomou corpo num conjunto de instituições e valores que se tornaram, assim, tradições (modernas).

Esse processo, entretanto, não ocorreu de forma consciente. No entendimento de Beck, a passagem para a sociedade de risco " $[. .$.$] ocorre de$ forma indesejada, despercebida e compulsiva no despertar do dinamismo autônomo da modernização, seguindo o padrão dos efeitos colaterais latentes" (GIDDENS; BECK; LASH, 1997, p. 16)². Especialmente, o re-

Esse trecho é bastante elucidativo para o escopo de diferenciação, sob a perspectiva de Beck, dos termos "reflexividade" e "reflexão", e a relação deles com o processo de emergência da sociedade de risco. No entendimento de Beck, a passagem da sociedade industrial para a sociedade de risco se dá de forma reflexiva (modernização reflexiva), no sentido de reflexividade. A este termo, o autor relaciona a percepção de que ocorre uma "autoconfrontação" da sociedade industrial com suas próprias bases, de modo que os efeitos da sociedade de risco não podem ser tratados e assimilados dentro dessa realidade - isso significa o retorno da incerteza. Assim, a passagem ocorre não por meio de reflexão, de forma consciente, mas pelo não conhecimento - o não visto e o não desejado (os efeitos 
conhecimento dessa nova realidade, vai ocorrer mediante a transição dos efeitos perniciosos da produção industrial da condição de "efeitos colaterais latentes" para a sua percepção como riscos decorrentes da aplicação da ciência, gerando modificações na ciência e na política.

Tal transição desenvolveu-se pelo lento processo (de convivência e) de passagem do predomínio da lógica da distribuição dos riscos sobre a lógica da distribuição da riqueza. A distribuição da riqueza foi a lógica dominante na sociedade industrial, chamada também de "sociedade da escassez" (BECK, 2010). Nessa busca pelo fornecimento de melhores condições de vida à população, o Estado de bem estar social viu-se pressionado a aumentar cada vez mais a produção de bens para a concretização de tal demanda, o que certamente exigiu o uso mais intenso de recursos naturais. Nessa perspectiva, segundo Pureza (1997, p. 13),

[...] embora o Estado Social signifique uma inclusão dos trabalhadores na esfera da cidadania, permanece um fundo de exclusão exactamente com o mesmo sentido que possuía no Estado liberal: os que não têm acesso ao mercado [...] e a natureza são ignorados $[\ldots]$

Esse cenário, portanto, foi se alterando com o desenrolar da segunda modernidade, justamente na medida em que os referidos efeitos colaterais latentes resultantes da produção foram reconhecidos como riscos. Esse reconhecimento, ao desnudar o problema dos riscos, possibilita uma quebra no consenso em torno do progresso, visto que fragiliza suas premissas fundamentais, quais sejam: a) a partilhada fórmula de que progresso econômico é igual a progresso social; b) a separação dos efeitos negativos do progresso econômico, que devem ser vistos como problemas residuais - os quais afetam a grupos específicos que não têm condições de questionar sua produção. Com o reconhecimento dos riscos, a equivalência entre progresso econômico e progresso social é quebrada, já que

colaterais latentes) é que permitem fazer surgir (e que caracterizam) a sociedade de risco. Essa percepção a respeito do mecanismo autônomo e impensado de transição não impede que, em um segundo momento, como de fato expõe o próprio autor, os elementos da sociedade de risco se tornem alvo de debate público (reflexão). 
todos são atingidos potencialmente por eles - inclusive grupos que têm poder de questioná-los.

Dessa forma, segundo Beck (2010, p. 247), a ciência tem suas próprias bases colocadas sob crítica; torna-se indispensável e, simultaneamente, insuficiente para explicar o mundo. Essa ruptura conduz a muitas modificações na relação da ciência com a práxis e com o espaço público. Inicia-se a desmistificação da ciência, que vai perdendo seu monopólio sobre o conhecimento e, então, sobre a verdade, o que conduz a um rearranjo dos processos de legitimação do que é válido socialmente. (BECK, 2010, p. 251)

Nessa linha, é preciso admitir que a ciência não é neutra para questionar a seriedade das definições conceituais realizadas, as quais interferem na tomada de decisão e, portanto, no processo de regulação jurídica deles (HERMITTE, 2005). Reconhecendo o elemento axiológico que perpassa as decisões realizadas dentro da ciência, renovam-se as perspectivas para sua relação com o exterior, com a práxis. Nesse processo renovado, faz-se viável a tentativa de desenvolver uma "capacidade prática de aprendizado" - da ciência como teoria junto com sua práxis respectiva. (BECK, 2010)

Nesse sentido, apesar de difícil, torna-se indispensável para uma ação dirigida à eliminação das origens dos riscos que o desenvolvimento da ciência e da tecnologia ocorra mediante a premissa da revogabilidade ${ }^{3}$ das decisões, de forma pedagógica, por meio do aprendizado - para que nenhuma decisão gere consequências que suspendam as alternativas decisórias das gerações futuras. Em sentido semelhante, Morin (2001) propõe o reconhecimento da necessidade de enfrentar as incertezas do conhecimento por meio da ecologia da ação, a qual propõe sopesar o circuito risco/precaução - além dos circuitos fins/meios e ação/contexto - como aspecto indispensável para lidar com o futuro.

Em segundo momento, consequência primordial do reconhecimento do risco é o potencial político que ele possui e desenvolve - aspec-

3 O termo "revogabilidade" é utilizado no sentido proposto por Beck, de evitar decisões que tragam resultados irreversíveis. (BECK, 2010, p. 270) 
to essencial para esse trabalho e base de compreensão da parte prática dessa pesquisa. Apesar da dependência da ciência para a identificação e interpretação dos riscos, a sua perda de poder para dizer qual é a verdade implica uma abertura a processos sociais de definição do que eles são e significam - de modo que, paradoxalmente, ela se torna também cada vez menos satisfatória. Assim, os riscos que passam a ser reconhecidos socialmente, têm sua definição e redefinição abertas à população, na tentativa e possibilidade de incorporar as demandas de movimentos sociais, para além do monopólio da verdade pela ciência.

Desencadeiam-se, portanto, segundo Beck, disputas entre várias racionalidades $^{4}$ (especialmente a científica e a social), que servem de base argumentativa para discussões em ambientes políticos - com suas respectivas tomadas de decisão (Parlamento e empresas, por exemplo). Nessa esteira, observa-se que o sistema técnico-econômico, cujas decisões apresentam-se ausentes de legitimação democrática, passa a ser alvo de disputa de definições nas quais a população - através da mídia, do judiciário e dos movimentos sociais - atua de alguma forma, o que conduz à formação de um terreno intermediário entre a política e a não política. Segundo Hermitte (2005, p. 9),

Essa inovação do objeto técnico em objeto político é o resultado de uma mudança cultural: a percepção dos riscos e do momento de seu possível controle mudou (I); a recusa de seu caráter inelutável renova as relações entre a ciência e a política (II) e se inscreve num contexto mais amplo da irrupção dos governados nos campos do poder, reservados, a princípio, aos governantes (III).

Tal irrupção dos governados pode ser muito bem exemplificada pela emergência dos novos movimentos sociais - tidos como exteriores ao sistema político tradicional, inclusive em razão da preferência por uma atuação não institucional (SANTOS, 1991) - que coloca em questiona-

4 No sentido da existência de diferentes racionalidades, Enrique Leff (2006), questionando a racionalidade econômica (técnica) predominante na atualidade, propõe a construção de uma racionalidade ambiental, que englobe quatro esferas de racionalidade: substantiva, teórica, técnica e cultural. 
mento as limitações das instituições políticas modernas. Nessa linha, os novos movimentos sociais surgem como reação à política centralizadora do Estado de bem estar social, requerendo mais espaço nas discussões públicas. Dessa forma, no entendimento de Santos (1991, p. 170), tem-se que

A novidade dos NMSs [novos movimentos sociais] não reside na recusa da política mas, ao contrário, no alargamento da política para além do marco liberal da distinção entre Estado e sociedade civil. [...] A politização do social, do cultural e, mesmo, do pessoal abre um campo imenso para o exercício da cidadania e revela, no mesmo passo, as limitações da cidadania de extracção liberal, inclusive da cidadania social, circunscrita ao marco do Estado e do político por ele constituído.

As instituições políticas modernas, categoricamente centralizadas, sofrem descrédito na sua capacidade de recepcionar e traduzir demandas, o que proporciona uma dissolução das fronteiras da política (BECK, 2010) em direção à ampliação de seu espectro, de seus atores e, possivelmente, de suas instituições - aspecto relevante para essa pesquisa. Nesse sentido, observa-se que a permeabilidade entre os riscos naturais, tecnológicos e sociais ocasionam uma maior abertura ao seu processo de definição, na medida em que a compreensão estritamente científica já não basta para solucionar os desafios que deles decorrem.

Em razão disso, impõe-se compreender, ainda que brevemente, o percurso desenvolvido no entendimento a respeito dos meios de definição dos riscos, na tentativa de proporcionar reflexões a respeito do papel que variáveis como a cultura e a sociedade podem possuir em tal percurso. Igualmente, esse intento auxiliará na interpretação realizada sobre o referido processo no licenciamento ambiental do OSX-Estaleiro/SC.

\subsection{Percepção e Construção Social do Risco: o processo de definição do risco ambiental}

Nesse momento, tem-se como foco a problemática da definição dos riscos como tais, a partir do que, então, o Direito precisa agir para regulamentar medidas que evitem a sua ocorrência, mas também que atuem 
frente à produção de consequências. Afinal, é mediante a definição dos riscos que se processa o movimento para seu planejamento e gestão. Nesse caminho, impõe-se compreender os elementos essenciais presentes nos debates que envolvem sociólogos realistas e construtivistas a respeito da definição dos riscos.

Inicialmente, faz-se necessário esclarecer que a problemática da definição dos riscos assume relevância nas ciências sociais a partir das críticas levantadas à abordagem técnica-quantitativa dos riscos (abordagem realista). Essa abordagem defende que os riscos são definidos por procedimentos técnico-científicos, baseados na estimação. Segundo Guivant (1998, p. 4),

A estimação dos riscos inclui a caracterização das fontes de risco, a medição da intensidade, frequência, duração das exposições aos agentes produzidos pelas fontes de risco e a caracterização das relações entre as doses e as consequências para as populações afetadas.

Assim, para essa abordagem, os leigos (em oposição aos peritos) são vistos praticamente como seres irracionais, que apenas percebem os riscos (ou não), de modo diferente ao que a ciência identificou, qualificou e quantificou. Nesse sentido, essa abordagem dos riscos realiza a sua definição sem considerar a interação dos seres humanos, em suas diferentes culturas, para a produção do risco e a geração de danos; mantém intacta a separação ortodoxa da ciência entre teoria e práxis.

Percebendo-se a crise da crença no mito do progresso e, portanto, a insuficiência dessas previsões matemáticas realizadas de modo isolado à sociedade para a qual se aplicam, a partir de 1960 é formulada uma das primeiras fortes críticas a essa concepção - a teoria cultural dos riscos, de Mary Douglas (antropóloga inglesa). O principal enfoque de Mary Douglas, segundo Guivant (1998), é o reconhecimento de que os fatores sociais devem ser considerados na análise dos riscos - e não afastados como algo que pudesse prejudicar a neutralidade do estudo.

Dessa forma, 
[...] uma análise mais completa deveria considerar as transformações da imagem como resultado de uma focalização mais precisa tanto sobre a sociedade [...] e sua cultura, como sobre as formas em que os indivíduos avaliam os riscos. (GUIVANT, 1998, p. 8)

Um risco é muito ou pouco percebido em razão de elementos relacionados com o processo sociocultural que envolve determinada sociedade, com seus valores e instituições.

As análises sociais do risco são difundidas e ganham bastante força na sociologia ambiental, a partir de 1980, com a perspectiva construtivista. Os autores que aprofundam esse aspecto ressaltam as críticas à simples percepção do risco, ao denotar a crise da crença na ciência e, portanto, a disputa de diferentes racionalidades: é a chamada construção social do risco. (GUIVANT, 1998)

A perspectiva construtivista, entretanto, pelo impacto que gerou na sociologia, levantou também muitas críticas, especialmente por aqueles que se intitulam realistas. Nesse sentido, segundo Hannigan (2009, p. 52), "[...] construcionistas sociais são rotineiramente criticados por negarem que a terra está cercada de uma série de tragédias ambientais, que vai de vazamento nuclear ao aquecimento global"s. Tais críticas, contudo, não se sustentam, já que a perspectiva construtivista tem como finalidade trazer em destaque os processos sociais, políticos e culturais envolvidos na compreensão e definição dos riscos - essencialmente porque é com base no que é reconhecido como risco (aceitável e não aceitável) que podem ser elaboradas leis, políticas públicas, decisões judiciais, dentre outras formas de gestão e de distribuição do risco ambiental. Nessa esteira, para Hannigan (2009, p. 55), “[...] a ordem de problema ambiental reivindicada pelos atores sociais nem sempre corresponde a necessidade real; ao invés disso, reflete a agenda de natureza política".

Nessa perspectiva, tem-se que a percepção de Beck (2010) comporta uma preocupação em transcender a referida dicotomia realismo $\mathrm{x}$

5 A terminologia adotada - construcionista - provavelmente se deve à tradução. Entretanto, trata-se da mesma corrente antes denominada construtivista. (HANNIGAN, 2009, p. 52) 
construtivismo, na medida em que ele afirma que a ciência é necessária, mas insuficiente, buscando conjugar a perspectiva científica com a social por meio do conceito de "relações de definição": "[...] as relações de definição da sociedade de risco incluem as regras, instituições e capacidades específicas que estruturam a identificação e avaliação do risco em um contexto cultural específico" (BECK, 2001, p. 237). No entendimento de Guivant (2001, p. 99),

A confluência entre a perspectiva realista e a construtivista estaria no cerne da teoria da sociedade global dos riscos. [...] Isto é, os riscos existem e não são meramente uma construção social, mas a sua transformação depende de como são percebidos socialmente.

Assim, entendendo como indispensável à consideração dos elementos sociais e culturais no processo de definição de riscos ambientais, tende-se a aproximar de tal processo a relevância da perspectiva da comunidade envolvida com os empreendimentos possivelmente causadores de riscos ambientais. É na esteira da abertura do monopólio da ciência para a disputa de diferentes racionalidades que se insere a indispensabilidade da participação popular ${ }^{6}$ em tomadas de decisão que envolvam questões ambientais.

Entretanto, para que a consideração da atuação da população não ocorra de forma acrítica e descontextualizada, é preciso ressaltar demais aspectos relacionados com o referido processo de identificação e definição dos riscos ambientais. Mostra-se imperioso refletir a respeito das condições materiais de vida das comunidades em que esse processo é realizado ${ }^{7}$. A fim de propiciar o desenvolvimento de uma percepção crítica a respeito do fenômeno, trabalhar-se-á com a nova noção de justiça ambiental.

\footnotetext{
6 Neste artigo, o tema da participação popular não é aspecto central de análise em termos teóricos, ainda que seja elemento subjacente à reflexão aqui abordada. Para saber mais sobre o processo de participação popular em si no licenciamento ambiental do OSXEstaleiro/SC, ver Christmann (2013).

7 Reconhece-se como premissa desses processos a indispensabilidade de acesso à informação e a existência de educação ambiental. Sobre o tema, vide: Christmann (2011).
} 


\subsection{Justiça Ambiental: uma reaproximação das dimensões social e am- biental da realidade}

Não obstante o grande mérito da teoria de Ulrich Beck (2010) em colocar em evidência os problemas ambientais surgidos pela aplicação da ciência e da tecnologia e a consequente politização das tomadas de decisão que envolvam riscos ambientais, ela não deixa de ser alvo de críticas por outros autores, sob os mais diferentes enfoques. Dentre essas diversas críticas (COSTA, 2004), que perpassam questões epistemológicas, metodológicas e alcançam, inclusive, algumas definições principais para a obra do autor, existe uma crítica mais ampla que precisa ser enfrentada. Trata-se, eminentemente, da questão representada pela seguinte pergunta: é possível afirmar que os problemas decorrentes da emergente sociedade de risco significam a superação das dificuldades observadas no contexto de sociedades de escassez ${ }^{8}$ Nessa linha de raciocínio, acrescenta-se uma segunda pergunta: é possível afirmar que o risco é democrático? A resposta que se entende como adequada a essa questão é negativa; buscar-se-á, frente a isso, apresentar as razões de cunho teórico e prático que permitam fundamentar esse entendimento.

Inicialmente, entende-se relevante destacar o que Cavedon (2010) observa como uma tendência, consistente na aproximação das concepções teóricas de direitos fundamentais e da questão ambiental. De certa forma, a questão ambiental propõe, dentre outras, uma reflexão profunda em busca de novas bases éticas que ressaltem a importância dos membros não racionais da vida e a indispensabilidade do seu tratamento por uma visão menos instrumental. Assim, em certo sentido, a questão ambiental, ao proporcionar o questionamento da concepção moderna hegemônica $\left(\right.$ antropocêntrica $\left.^{9}\right)$ a respeito da relação do ser humano com a natureza,

\footnotetext{
8 Não se ignora a breve referência de Beck, na obra aqui trabalhada, ao fato de que aqueles que possuem maiores acessos à informação e poder aquisitivo razoável têm melhores condições de se proteger dos riscos. Porém, entende-se que essas ressalvas são apresentadas como exceção à realidade global, o que não retrata adequadamente os processos predominantes na atualidade.

9 Designa-se por antropocentrismo o entendimento hegemônico a respeito da relação do ser humano com a natureza que se elaborou no processo de constituição da modernidade como resultado da concepção paradigmática cartesiano-mecanicista de mundo. Nesse
} 
coloca em contestação a visualização daquele como único sujeito a ser protegido pelo direito.

Em alguns aspectos, tal contestação pode gerar certa oposição entre os direitos fundamentais do ser humano e a questão ambiental, em sua demanda por proteção do meio ambiente. Os problemas de articulação entre os direitos fundamentais e a proteção à natureza, em termos epistemológicos, residem exatamente no deslocamento do ser humano do centro do mundo - ou, mais especificamente na área do direito, como único alvo de proteção por parte dos Estados; esse embate é reflexo da dificuldade existente em definir o limiar entre o vínculo e o limite (OST, 1995) que relaciona os dois elementos: natureza e ser humano. Os empecilhos para a tutela jurídica de ambos podem ser muito bem representados pelo seguinte questionamento, proposto por Acselrad (2010a, p. 103-4): “[...] como conquistar legitimidade para as questões ambientais, quando, com frequência, a preocupação com o ambiente é apresentada como um obstáculo ao enfrentamento do desemprego e à superação da pobreza?”.

Porém, não é pelo fato de essa tutela jurídica conjunta ser complexa que a dimensão social e a dimensão ambiental devam ser colocadas como opostas excludentes. Impõe-se trabalhar essas ideias em busca do que Ayala (2010, p. 235, grifos do autor) chama de "um diálogo possível":

O possivel deixa, dessa forma, de ser socialmente reproduzido como expressão que identifica condições de imobilismo ou de impotência perante um futuro ainda inacessivel, desconhecido e incompreensivel, para assumir a qualidade de objetivo e compromisso jurídico tendente à concretização, tarefas que dependem da satisfação de severos compromissos de solidariedade.

Nesse sentido, compreende-se como necessária tal aproximação visto que ela pode proporcionar uma perspectiva mais ampla e potencialmente completa a respeito dos conflitos existentes, na medida em que procura conjugar a dimensão social, política, econômica, cultural, dentre

sentido, o antropocentrismo implica o entendimento de que está reservado ao ser humano o direito de dominar e aproveitar-se dos recursos naturais em razão da sua capacidade de pensar e agir embasado na razão. (CAPRA, 2006) 
outras, à dimensão ambiental da realidade (CAVEDON, 2010). Igualmente, nesse processo, torna-se possível ampliar a perspectiva a respeito de direitos subjetivos para incluir a proteção ao meio ambiente e possibilitar uma renovação de sua leitura, em consonância com a realidade atual em que a busca por soluções para o problema ambiental é tarefa inexorável. Também, segundo Cavedon (2010), a aproximação entre essas duas dimensões viabiliza a consideração simultânea e com igual relevância dos problemas oriundos da sociedade da escassez junto à sociedade de risco, na medida em que aproxima o social do ambiental.

A preocupação em aproximar a dimensão social do problema ambiental é reforçada na medida em que se percebe que a problemática apresentada, segundo Acselrad, Mello e Bezerra (2009, p. 11-15), converte-se em estratégia para naturalizar a ideia de que todos são igualmente afetados pelos efeitos da crise ambiental; em outras palavras, para imbuir a compreensão de que o risco ambiental é democrático. Essa percepção é problemática visto que ela promove o isolamento da dimensão ambiental, excluindo do debate os cenários em que se produzem e nos quais são sentidos os problemas ambientais - ou seja, o contexto em que os processos de definição dos riscos ocorrem.

Referida estratégia, cujo intuito é produzir um entendimento predominante, segundo Acselrad (2010a), está embasada em uma razão utilitária, que compreende o meio ambiente como recursos naturais a serem apropriados para a reprodução do sistema econômico - desprovido de elementos sociais e culturais múltiplos. Não questiona a finalidade subjacente à apropriação dos recursos, mas somente os meios (mais eficazes e rentáveis) a partir dos quais isso é feito. Como consequência, o meio ambiente é visto de forma homogênea e, portanto, os efeitos deletérios causados em sua apropriação também o são, de modo que a poluição e o risco ambiental se apresentam como democráticos.

Dessa perspectiva decorre, conforme Acselrad, Bezerra e Mello (2009), uma atuação direcionada pela afirmação do mercado, pela crença sobre o progresso técnico e por um falso consenso político, implicando a despolitização das lutas decorrentes desse cenário, por meio de decisões falsamente negociadas, visando à estabilidade. Por meio dessa perspecti- 
va, se fortalece a estratégia empresarial que pode ser chamada de "chantagem locacional", a qual se estrutura por meio de pressões - seja para a manutenção do empreendimento onde está ou para sua implantação em certo município, região ou país - tendo em vista a liberação de cumprimento de normais sociais e ambientais, além de vantagens tributárias. Assim, o investimento instala-se junto "[...] às populações mais destituídas ou a governos com maiores índices de desemprego e ameaça de crise social [...]" (ACSELRAD; MELLO; BEZERRA, 2009), impondo-lhes uma falsa liberdade de escolha de se submeter a tais condições e riscos.

Tendo em vista a hegemonia da perspectiva acima trabalhada, os questionamentos a respeito da desigualdade ambiental configurada pelas formas monopolistas de apropriação de recursos naturais e pelas opções discriminatórias de alocação de dejetos e exposição a riscos iniciaramse com reivindicações realizadas por movimentos de base social que, nos Estados Unidos, passaram a questionar a localização de indústrias químicas em regiões povoadas essencialmente por negros, conforme esclarece Bullard (2004, p. 41-68). Nasce, nesse contexto, a noção de justiça ambiental, entendida aqui como adequada para combater a razão utilitária predominante e, assim, fornecer bases teóricas críticas para a compreensão do processo de definição do risco ambiental na prática - o que é indispensável para uma perspicaz análise dos processos de definição dos riscos no caso concreto em estudo.

Com a expansão do movimento no Brasil e o desenvolvimento de explicações teóricas à própria realidade, identificou-se como causa original apta a explicar o processo de vulnerabilização (ACSELRAD, 2010b) de certos grupos - não obstante a existência de discriminação de raça, etnia e gênero - a desigualdade social (ACSELRAD; HERCULANO; PAIVA, 2004). Especificando referidas desigualdades, é possível explicitá-las nos seguintes elementos: desigualdade no acesso aos recursos naturais e aos resultados da produção para a qual esses recursos são direcionados (consumo); desigualdade no sofrimento do ônus decorrente da produção dos bens de consumo e demais utilizações, e desigualdade no acesso aos processos de tomada de decisão em que as desigualdades antes citadas são conformadas. 
Desse modo, Acselrad (2010a) apresentou a razão cultural para embasar a compreensão da questão ambiental. Assim, destacaram-se os questionamentos a respeito da finalidade (para quê e para quem) com que os recursos naturais são apropriados, e uma visão que identifica no meio ambiente, além de recursos naturais, elementos sociais e culturais, os quais geram diferentes formas de apropriação e distintas significações simbólicas. A partir disso, é possível compreender que "[...] os riscos ambientais [...] são diferenciados e desigualmente distribuídos, dada a diferente capacidade de os grupos sociais escaparem aos efeitos das fontes de tais riscos [...]" (ACSELRAD, 2010a, p. 109), em razão de seus diferentes contextos sociais e culturais.

Nessa medida, essa leitura possui o potencial de viabilizar um reencontro crítico entre as dimensões social e ambiental, ressaltando as sobreposições que decorrem da emergência da sociedade de risco em países como o Brasil, em que elementos da sociedade da escassez ainda são muito evidentes. A nova noção, ainda em construção, de justiça ambiental, portanto, segundo Cavedon (2004), auxilia na "ecologização"10 dos direitos fundamentais e na "humanização" do direito ambiental, estabelecendo uma ponte a fim de concretizar um diálogo possível.

Assim, por justiça ambiental designa-se o conjunto de princípios e práticas que: assegure que nenhum grupo social suporte parcela desproporcional de consequências negativas, oriunda de qualquer esfera de decisão; assegure equitativo acesso aos recursos ambientais do país; assegure acesso à informação e à participação nos processos de tomada de decisão sobre uso de recursos ambientais e destinação de resíduos; favoreça a constituição de sujeitos coletivos de direitos e movimentos sociais que lutem pela consolidação das premissas anteriores. (REDE BRASILEIRA DE JUSTIÇA AMBIENTAL, 2001)

Diante do exposto, compreende-se que o risco ambiental não é democrático; ao contrário, ele reconhece as condições de contestabilidade que uns e outros grupos sociais possuem, impondo-se predominantemen-

\footnotetext{
${ }^{10}$ O termo é empregado no sentido que Canotilho o utiliza, ao tratar da ecologização do direito. (CANOTILHO, 1995, p. 69-79)

11 Expressão empregada por Cavedon (2004).
} 
te sobre os desprovidos de condições materiais, informacionais e de poder para se posicionarem contrários ao ônus de uma atividade da qual, dificilmente, gozarão dos benefícios. Em razão disso, sob a perspectiva apresentada pela justiça ambiental, torna-se possível reaproximar a dimensão social da questão ambiental, de modo a conjugá-las como um único objetivo: proteção ambiental e justiça social somente podem existir plenamente caso sejam promovidas simultaneamente.

Dessa forma, a partir da base teórica que é fornecida pela noção de justiça ambiental, em conjunto com os questionamentos levantados pela teoria da sociedade de risco, percebe-se, já na teoria, a complexidade que envolve o processo de definição dos riscos socioambientais, em que ciência e sociedade atuam complementarmente, seja em oposição, seja em cooperação. É a partir dessas concepções que se busca compreender o contexto do caso concreto que serviu de objeto de estudo.

\section{O Licenciamento Ambiental do OSX-Estaleiro/SC e os Proces- sos de Definição do Risco Ambiental}

O caso concreto que serviu de objeto de estudo foi o procedimento de licenciamento ambiental do OSX-Estaleiro/SC, no Município de Biguaçu, que se desenvolveu ao longo dos anos 2009 e 2010, cujo empreendimento a ser licenciado consistia em fabricação e reparos de embarcações e estruturas flutuantes (indústria de material de transporte). O licenciamento ambiental é um instrumento legal direcionado aos processos de gestão ambiental, na medida em que visa organizar o uso e o aproveitamento de recursos disponíveis - sopesando riscos presentes e futuros, na medida em que faz a gestão do risco ambiental. Nos termos do artigo $1^{\circ}$, I, da Resolução n. 237/97 do CONAMA (BRASIL, 1997), o licenciamento ambiental constitui-se um procedimento administrativo ${ }^{12}$, conduzido pelo órgão ambiental competente, que visa licenciar a localização, instalação, ampliação e operação de atividades que utilizem recursos

12 Conceitua-se procedimento como "[...] uma sucessão de atos preparatórios que devem obrigatoriamente preceder a prática do ato final [...]", nos termos previstos em lei. (DI PIETRO, 2008, p. 589, grifos da autora) 
ambientais e sejam consideradas efetiva ou potencialmente poluidoras ou degradadoras. (BRASIL; CONAMA, 1986)

A pesquisa documental, consistente na análise da documentação original do referido procedimento administrativo, permitiu a identificação dos grupos que interviram formalmente no processo em questão e que adotaram um posicionamento oficial frente ao caso. Utilizando-se conceitos jurídico-legais, optou-se por tratar esses diferentes grupos sob a roupagem em que eles mesmos se identificaram no processo: em termos gerais, como associações. Nessa pesquisa, entendeu-se como associação ${ }^{13}$ um conjunto de sujeitos que unem suas forças para perseguir objetivos comuns não lucrativos.

Mostrando-se inviável a realização de entrevista com todas as associações que atuaram (mais de 40), buscou-se verificar a variedade do objetivo existente na constituição de cada uma, assim como a localização delas, visto que o licenciamento ambiental em estudo compreendia como área de influência (indireta) os Municípios de Biguaçu, Governador Celso Ramos e Florianópolis. Identificou-se a existência de cinco tipos de associações: de moradores de bairro; de pescadores; de maricultores; de proteção do meio ambiente e de sociedades empresárias elou empresários. Assim, partiu-se de um número de 17 entrevistas como parâmetro, tendo sido atingida a saturação após serem realizadas 14 entrevistas. Entendeuse que esse número foi suficiente para alcançar um satisfatório grau de aprofundamento, abrangência e diversidade no processo de compreensão a respeito do caso em estudo.

Para a compreensão dos processos de definição dos riscos pela população atuante, procurou-se enfocar os elementos apresentados no Estudo Prévio de Impacto Ambiental (EPIA) que, identificados e interpretados pelas comunidades, serviram para embasar a percepção em torno dos efeitos resultantes do empreendimento por cada uma delas. O Estudo Pré-

13 Parte-se da conceituação apresentada pelo Código Civil/2002, para definir as associações (civis), no seu artigo 53. No caso do presente trabalho, adota-se a nomeação associações em sentido lato, visto que se pretende englobar entidades formadas sob esse intuito, mas mediante regulamentação jurídica distinta - e, portanto, natureza jurídica diferente da associação civil. As especificações serão realizadas no momento oportuno. 
vio de Impacto Ambiental (EPIA) é um estudo documentado e apresentado no licenciamento ambiental que possui como objetivo fornecer informações sobre a situação do ambiente envolvido com o empreendimento, assim como a respeito dos possíveis e potenciais impactos ambientais, socioeconômicos e culturais a serem gerados por ele; está previsto genericamente no artigo $9^{\circ}$, III, da Lei n. 6.938/81.

Nota-se, portanto, que a divulgação e discussão do EIA/RIMA figura um momento crucial de identificação de impactos ambientais certos, prováveis, possíveis e potenciais, de modo que tais documentos devem se tornar alvo de intenso e disputado debate em torno de suas resoluções. Considerando a previsão de um grande número de possíveis impactos socioambientais (como a dragagem do fundo do mar para obtenção da profundidade necessária para passagem das embarcações e impactos nas unidades de conservação próximas), aqueles que mais foram alvo de debate no contexto das argumentações apresentadas por pessoas físicas e associações, são a troca da água de lastro e os efeitos para a pesca e a maricultura artesanal.

Em poucas palavras, a água de lastro é uma quantidade de água que se mantém nos porões de navios de carga como contrapeso, no intuito de conferir equilíbrio à embarcação. Ela é recolhida ao navio quando esse deixa o porto ou lugar em que se encontra e é despejada de volta ao mar, quando a embarcação se aproxima de seu destino. Nesse processo, espécies do lugar de saída são liberadas fora de seu habitat normal, o que significa, para o novo habitat, a introdução de espécies exóticas. Quanto à pesca artesanal, o RIMA apontou a possibilidade de redução na disponibilidade de pescado e a supressão de áreas de pesca (que ocorreria com certeza, temporariamente, durante a fase de dragagem). A respeito da maricultura, o RIMA destacou a possibilidade de aumento de material em suspensão na coluna d'água devido às obras de dragagem - o que deixa a água mais turva, prejudicando a alimentação dos moluscos - e consequências decorrentes da proximidade com algumas áreas de cultivo.

Frente a essas informações constantes no RIMA, o processo de identificação e interpretação dos possíveis efeitos gerados pelo empreendimento transcorreu de modo que as próprias comunidades desenvolve- 
ram seus processos de definição dos riscos. Nesse sentido, destaca-se a referência de muitos deles no sentido de que o entendimento defendido se consubstanciava na verdade. Entende-se, portanto, que as compreensões apresentadas sobre o empreendimento em si e sobre o próprio processo se constituíram em aberturas para diversas racionalidades, ou seja, em uma disputa pela própria elaboração d'A Verdade a respeitos dos riscos sociais e ambientais: em legítimos processos de construção social do risco, conforme abordado. Nesse sentido, buscar-se-á destacar os principais elementos dessas construções, considerando os contextos sociais e culturais das comunidades, organizados sob a categoria de pesquisa "Construindo as definições dos riscos: os efeitos do empreendimento".

\subsection{Construindo as Definições dos Riscos: os efeitos do empreendimento}

Essa categoria de pesquisa teve como objetivo retratar os efeitos que, no contexto de vida dos membros de cada uma das associações, foram registrados com maior evidência e, portanto, orientaram o processo de definição dos riscos sociais e ambientais. Nesse sentido, ressalta-se que os efeitos do empreendimento foram apresentados, pela grande maioria das associações, como especialmente relacionados com um ou outro dos seguintes aspectos, identificados sob designação genérica como: geração de empregos versus degradação ambiental.

As associações que identificaram como principal efeito decorrente do empreendimento a geração de emprego e renda posicionaram-se a favor dele. $\mathrm{O}$ entendimento de que o projeto do estaleiro geraria emprego e renda foi bastante enfatizado pela própria empresa, que afirmou a geração de aproximadamente 3.500 empregos diretos na fase de implantação e 4.000 empregos diretos na fase de operação - além dos empregos indiretos gerados por outras empresas secundárias, totalizando, no mínimo, 8.000 empregos, chegando potencialmente a 12.000 empregos totais (CARUSO Jr., 2010, p. 9-10). Com maior número de pessoas empregadas, como consequência haveria um maior consumo de serviços e produtos, de modo a viabilizar a geração do "efeito renda" 14 . Por fim, consideran-

${ }^{14} \mathrm{O}$ "efeito renda" é apresentado pelo empreendedor como as consequências para a economia, decorrentes do aumento do consumo pela injeção de valores - no caso, 
do que a empresa afirmava ter condições de, mediante o oferecimento de cursos profissionalizantes, contratar a maioria da mão de obra na Grande Florianópolis, a perspectiva de desenvolvimento da região, conforme entenderam os entrevistados, mostrou-se muito promissora.

No contexto da amostra qualitativa definida para essa pesquisa, dentre as catorze associações que tiveram representantes entrevistados, a imensa maioria das que focaram na geração de emprego e renda como efeitos do empreendimento estão relacionadas com a comunidade de Biguaçu. Esse foi, dentre os três formalmente envolvidos no procedimento de licenciamento ambiental, o Município que se mostrou fortemente a favor da instalação do empreendimento. Assim, as três associações de moradores (bairros), a colônia de pescadores e a associação de maricultores de Biguaçu manifestaram-se fortemente (ao menos no posicionamento oficial, transmitido pelo representante entrevistado) a favor do projeto do estaleiro pelas razões acima apontadas (somando, ao total, seis das 14 associações). Ainda, nesse grupo, também arrolando a questão de geração de emprego e renda, mas, simultaneamente, destacando-se a especificidade decorrente dos objetivos da entidade, uma associação de empresários e sociedades empresárias do setor náutico manifestou apoio ao empreendimento pela possibilidade de geração de negócios aos seus sócios. Algumas falas ilustram o apontado:

Então, a pesca, ela tem uma defasagem muito grande, né? E a preocupação nossa, agora, são nossos filhos, nossos netos, essa juventude que está vindo aí, a maioria sem emprego nenhum. A empresa tava oferecendo (inaudível - $15 \min 44 \mathrm{~s}$ a $15 \min 45 \mathrm{~s}$ ) curso profissionalizante, que é um ponto positivo muito bom. Profissionalizou um monte (inaudível - 15 min 48 s a $15 \min 49$ s) de gente pra trabalhar, dentro da própria empresa ${ }^{15}$.

Emprego, principalmente ia gerar muito emprego. Porque hoje o que mais nós tamos precisando é geração de emprego. Emprego, renda, que seria criado pelas famílias que viessem procurar emprego.

decorrente dos empregos gerados pelo estaleiro, que movimentariam e impulsionariam o setor de serviços.

15 Colônia de Pescadores de Biguaçu. 
E a visão de futuro que vem pra nossa comunidade, né, a melhoria, infra-estrutura pro lugar, afinal, ia crescer bastante. Foi uma pena não ter vindo, né ${ }^{16}$.

No outro lado, tem-se a maioria das associações entrevistadas, essencialmente relacionadas com Governador Celso Ramos e Florianópolis que, em menor ou maior intensidade, com diferentes matizes relacionados às especificidades de cada uma delas, adotaram posição contrária à instalação do empreendimento com base na possibilidade de degradação ambiental. Nesse sentido, em termos gerais, posicionaram-se associações de bairro de Florianópolis e Governador Celso Ramos, as ONGs ambientalistas, colônia de pescadores e associação de maricultores de Governador Celso Ramos, e a associação de empresas de aquicultura.

Observa-se, logo, que esse conjunto de associações que se mostraram desfavoráveis à implantação do projeto é bastante heterogêneo, tanto em termos dos objetivos de constituição quanto à localização geográfica de cada uma das associações que o compõem. Apesar de diferenças no que se refere aos direitos e interesses afetados, a degradação ambiental, como base de argumentação, está presente em todas elas. Destacam-se alguns trechos que ressaltam essa semelhança:

Olha, o que veio, o que deixou claro pra gente, [...], foi... é o que eles disseram pra gente, o que a gente viu, assim, que aquilo ali... a gente achava e a gente também teve noção da coisa porque a gente via que ia ter um impacto ali. Aquilo ali ia sofrer algo... não sei! [...] Mas o mar, ali a parte ali do solo, aquilo ali ia receber uma mudança, uma mudança ${ }^{17}$.

$\mathrm{Na}$ verdade, a nossa visão sempre foi de um problema ambiental de impacto muito grande. Um Estaleiro ele traz problemas de poluição, contaminando... [...]. Então a gente teria ali um problema de resíduos químicos, certo? Água de lastros, toda uma dragagem, processo ambiental também que iria acontecer ali ${ }^{18}$.

\footnotetext{
16 Associação de moradores de bairro de Biguaçu (número 1).

17 Colônia de Pescadores de Governador Celso Ramos.

18 Associação de empresários de aquicultura
} 
Então, não precisava nem ter olhado a lista de espécies de peixes pra gente se posicionar contra, porque tão ali 3 áreas de conservação! A única reserva biológica marinha do Brasil... o único espaço de toda ZEE - zona econômica exclusiva marinha do país - onde o Estado falou "não, aqui é reserva biológica!" 19 .

Inclusive, de fazer exigências públicas de que a empresa jamais na hipótese de vir a se instalar - poderia, poderia vir a alegar que qualquer espécie de erosão teria sido por um motivo, fato da natureza. Porque a partir do momento que um empreendimento daquele porte quebrasse o equilíbrio natural, não poderia mais culpar a natureza $^{20}$.

A partir de tal base argumentativa em comum, sem dúvida, é possível observar diferentes perspectivas a respeito dos resultados decorrentes deste efeito, em termos gerais, a partir da identificação do objetivo em comum entre as pessoas que criam uma associação. Assim, no caso das associações de moradores de Florianópolis, foi possível perceber preocupação relacionada com a manutenção das formas de vida da região - relacionada com a pesca, a maricultura, a gastronomia e o turismo existentes - e do espaço de convivência e lazer público da comunidade (as praias). No que se refere à associação de maricultores, à associação de empresas de aquicultura e à colônia de pescadores de Governador Celso Ramos, o receio se relacionava com as consequências para a qualidade da água (maricultura/aquicultura), para a preservação dos criadouros de camarão e às mudanças para a pesca decorrentes da dragagem. Sobre a dragagem, um dos entrevistados se manifestou, afirmando:

[...] que eles iam fazer [um buraco] de 10 metros de profundidade por 200 metros de largura, que ia prejudicar o nosso pescador por meio da, da, a rede de caça, que é o caceio... porque ali ela, a maré que leva, a maré que traz. Tanto o nosso pescador, que achava que a rede ia se sumir naquele buraco, naquele... alguma coisa ia existir ${ }^{21}$.

\footnotetext{
19 ONG ambientalista (número 2)

20 Associação de moradores de bairro de Florianópolis (número 2)

21 Colônia de Pescadores de Governador Celso Ramos.
} 
Foi possível compreender pela fala de alguns entrevistados, especialmente os representantes de comunidades de pescadores e maricultores, mas também de associação de moradores, que o receio decorrente da incerteza a respeito das consequências relacionadas com a implantação do projeto direcionou-os para um entendimento mais cauteloso e, por fim, para uma posição contrária ao empreendimento. Percebeu-se que o apreço pelo modo de vida que cultivam superou a importância - por alguns entrevistados, ressaltada - que uma possível geração de empregos possui.

Nesses termos, compreende-se que a maioria das associações adotou posicionamentos a favor ou contra o estaleiro com base, essencialmente, em dois possíveis efeitos principais. De qualquer forma, entretanto, ambos os posicionamentos estão relacionados com o contexto social, econômico e cultural em que se inserem. Para a compreensão desses elementos, assim como para a percepção de outros fatores relevantes, passase à tentativa de realizar o encontro dialético entre a teoria apresentada no início e os resultados obtidos no caso prático.

\subsection{Teoria e Prática: as dificuldades nos processos de definição do ris- co socioambiental}

Os problemas resultantes da emergência da sociedade de risco em países como o Brasil - que não passaram pelo processo de consolidação de um Estado de bem estar social que tenha possibilitado o acesso da imensa maioria da população a condições de vida social, econômica e cultural mais dignas - mostram-se muito mais explosivos e dramáticos. O risco ambiental se sobrepõe com mais severidade àqueles já expostos a riscos sociais, econômicos e culturais, intensificando cenários de desigualdade social com novos matizes ambientais - nos termos do que, teoricamente, a noção de justiça ambiental possibilitou desnudar. Nesse contexto conflituoso, instrumentos legais como o procedimento administrativo de licenciamento ambiental em estudo mostram-se como oportunidades direcionadas à gestão do risco ambiental.

Tratando-se de um processo que deve resultar em uma tomada de decisão a respeito da liberação ou não do empreendimento, entende-se, a partir da base teórica traçada, como indispensável a realização de um 
debate em torno da existência de riscos sociais e ambientais gerados, relacionado com percepções sobre quais são esses riscos e de como eles são produzidos (processo de definição dos riscos) e sobre como eles são distribuídos entre os potencialmente atingidos. Enfim, a tomada de decisão pelo poder público precisa considerar a forma como a população envolvida percebe e compreende os riscos, a fim de construir uma noção de risco ambiental mais rica e plural - e não simplesmente técnico-científica - para proceder a uma gestão dos riscos mais eficaz.

Entretanto, o embate existente entre as dimensões social e ambiental, em conflitos como o emergente do procedimento de licenciamento ambiental do OSX-Estaleiro/SC, apresenta sua faceta mais cruel justamente no processo de percepção e compreensão dos riscos ambientais pelos sujeitos potencialmente atingidos. Em termos gerais, os investimentos procuram se instalar próximos às populações mais necessitadas e menos organizadas e, nesses contextos, são ovacionados e desejados profundamente pelas populações em questão. Diante disso, segundo Acselrad, Mello e Bezerra (2009, p. 138), “[...] o processo de construção, por parte da população, do que ela entende por 'intolerável' e 'arriscado' é constrangido pelas condições impostas pelos grandes detentores da capacidade de investir".

Nesse sentido, foi possível perceber que o próprio processo de formulação da noção de riscos sociais e ambientais no caso concreto em estudo restou, ao menos parcialmente, prejudicado para as populações próximas à instalação do empreendimento. Fixados nas expectativas proporcionadas pela oportunidade de empregos, quase ignoraram a possibilidade de geração de sérios danos socioambientais.

Dessa forma, percebe-se que os resultados da pesquisa empírica em questão exemplificam as dificuldades existentes para a percepção e formulação, pela população, de quais são os potenciais e/ou prováveis riscos sociais e ambientais do processo. Especialmente para aquelas populações que são seduzidas pelas promessas de emprego e melhoria das condições de vida, o processo de identificação e qualificação de riscos sociais e ambientais é reduzido a uma questão de menor relevância - a um exagero, a uma mentira. Ressalta-se que, segundo a manifestação dos próprios en- 
trevistados, aqueles que relataram falta de oportunidades e a existência de um contingente de jovens desempregados, ou que se referiram a essa preocupação para o futuro, foram os que formularam a produção de efeitos como geração de emprego e renda. Alguns deles, além disso, foram muito enfáticos a respeito da grande perda que representou a não instalação do estaleiro na região - com testemunhos de profunda tristeza e desesperança.

[...] triste dizer que o estaleiro foi embora pra... Rio de Janeiro. Então pra nós foi uma perda muito grande, muito, muito.

O que eu tentei falar agora, é que eu espero que eles voltem, né... com essa... (inaudível), fazer hotel (inaudível)... é, shopping... só espero que eles vortem! Que não deixa nós nessa tristeza! Que não deixe esse pessoal que tá aguardando... a nossa esperança é essa! ${ }^{22}$.

Diferentemente, entre aqueles que identificaram como efeitos do empreendimento a degradação ambiental, nenhum relatou desesperança ou desemprego - nem mesmo como uma preocupação futura - como uma questão central para a associação (e a comunidade) que representa. As (diferentes) bases materiais de vida (social, econômica e cultural) das comunidades relacionadas com as associações entrevistadas mostraramse como um elemento extremamente relevante a condicionar as possibilidades de percepção e definição dos riscos sociais e ambientais. Na fala abaixo é possível perceber a maneira como a questão da degradação ambiental foi tratada - como algo que não era suficientemente importante para que a geração de empregos fosse preterida.

E como eu falei pra você, eu morei, eu me criei no lugar que ia ser feito o estaleiro. Então, o que eles alegaram que ia ter um impacto ambiental... (inaudível) eu não concordei com aquilo ali, não concordo. Acho que a coisa não é tão, tão grave como muita gente anunciou que ia ter impacto ambiental, que ia destruir o (inaudível $)^{23}$.

${ }^{22}$ Associação de moradores de Biguaçu (número 2)

${ }^{23}$ Associação de moradores de Biguaçu (número 1) 
Dessa maneira, foi viável compreender e, de certa forma, reforçar o entendimento esboçado a respeito da necessidade de visualizar o tema da proteção ambiental de maneira interligada aos direitos humanos fundamentais, adotando como prisma de observação a noção de justiça ambiental. As entrevistas realizadas demonstraram, especialmente no que se refere à percepção sobre os efeitos do empreendimento, que a tendência da população em mais frágeis condições sociais e econômicas seria a de aceitar, ou ignorar, os prováveis riscos ambientais gerados frente à premente necessidade de obter o seu sustento diário.

Nota-se, portanto, que a percepção e a definição dos riscos sociais e ambientais ou, em outras palavras, a construção do que é tolerável e do que é intolerável, por uma população, é um processo bastante complexo, em que realidade e representação são integradas. Conforme Acselrad, Mello e Bezerra (2009, p. 110), “[...] a poluição não está dada, cabendo aos sujeitos sociais percebê-la: ela é construída a partir de uma conjugação de fatores sociais, culturais e físicos". Nesse sentido, esse processo, chamado também de sensibilização ${ }^{24}$, pode ser facilitado ou dificultado - e, portanto, resultar em mobilização e organização política ou não - por questões como, dentre outras: a presença de entidades locais estruturadas (como associação de moradores) e a dependência econômica da população em relação ao empreendimento. (ACSELRAD; MELLO; BEZERRA, 2009, p. 114-120)

Tendo em vista esses elementos, torna-se viável identificar como premissa para o desenvolvimento dos processos de definição de risco por meio de uma participação popular consciente, a posse, pelos cidadãos, de um mínimo existencial socioambiental que lhes garanta as condições materiais de vida necessárias para uma compreensão da situação concreta, quanto aos seus efeitos (definições de risco), de forma independente. A garantia da existência do mínimo existencial socioambiental significa a incorporação da proteção ambiental, por meio do princípio do mínimo existencial ecológico (SARLET; FENSTERSEIFER, 2010), como dimensão constituinte do princípio da dignidade da pessoa humana no Estado brasileiro - a pedra fundamental do sistema constitucional cujo núcleo é

24 Termo usado por Acselrad, Mello e Bezerra (2009). 
representado pelo mínimo existencial essencial dos direitos fundamentais na realidade brasileira. Dessa forma, além da proteção da segurança jurídica e da busca pela justiça social, objetivos consagrados pelos Estados Liberal e Social, o Estado Constitucional Ecológico implica "[...] o reconhecimento da jusfundamentalidade do direito ao meio ambiente ecologicamente equilibrado [...]" (SARLET; FENSTERSEIFER, 2010, p. 25) para o completo desenvolvimento da personalidade humana ${ }^{25}$.

Tem-se, logo, que a participação popular poderá desenvolver-se de forma crítica caso os indivíduos envolvidos tenham acesso aos direitos sociais básicos, de modo que se mostre viável uma interpretação livre de condicionamentos - especialmente daqueles cujo peso seja tão significativo, como se apresenta a dependência ao próprio empreendimento para o alcance de tais direitos. Nesses termos, o princípio do mínimo existencial socioambiental, ao defender a inserção da questão ecológica como elemento do princípio da dignidade da pessoa humana, em conjunto com a questão social, apresenta-se como um instrumento relevante para o fortalecimento da reaproximação (crítica) das dimensões social e ambiental da realidade. Nesse sentido, no entendimento de Sarlet e Fensterseifer (2010, p. 15), tem-se que

O enfrentamento dos problemas ambientais e a opção por um desenvolvimento sustentável passam, portanto, necessariamente, pela correção do quadro alarmante de desigualdade social e da falta de acesso de expressivas partes da população aos seus direitos sociais básicos, o que, importa referir, também é causa de degradação ambiental.

Observou-se, portanto, que algumas comunidades não se mostraram aptas a desenvolver o direito de fala livre de pressões decorrentes das necessidades imediatas a que estão submetidas socialmente. Por essas razões, mediante o estudo deste caso concreto, entendeu-se que a ausência de um mínimo existencial socioambiental por parte dos participantes do

25 A incorporação da dimensão ambiental no núcleo da dignidade da pessoa humana impõe a ampliação da proibição do retrocesso também a esta dimensão: o Princípio da Proibição do Retrocesso Socioambiental. (SARLET; FENSTERSEIFER, 2010) 
processo mostrou-se como um evidente desafio à efetividade da participação popular na gestão do risco ambiental, consistente na impossibilidade de desenvolver uma construção social do risco que seja legítima e independente.

\section{Conclusão}

O presente artigo dedicou-se a problematizar o tema da participação popular na gestão do risco ambiental, tendo como enfoque principal os processos de definição do risco pelas comunidades envolvidas. Para isso, optou-se por uma abordagem dialética que relacionou base teórica e pesquisa empírica a fim de aprofundar o conhecimento em torno dos elementos que influenciam esses processos.

Dessa forma, a compreensão do contexto atual partiu da conformação da teoria da sociedade de risco, complementada pelo entendimento em torno da construção social do risco e problematizada, na realidade brasileira, pelos questionamentos e percepções que a noção de justiça ambiental carrega. A partir disso, a especificação do caso concreto que serviu de objeto de estudo e a apresentação dos resultados da pesquisa empírica viabilizaram a identificação de novos fatores influentes nos processos de definição do risco ambiental: essencialmente, a carência ou não de condições materiais para uma vida digna.

Foi possível concluir, portanto, mediante o reencontro da teoria com a prática, que a inexistência do respeito aos direitos sociais básicos das comunidades envolvidas nos processos de tomada de decisão que admitem a participação popular se constitui em uma dificuldade para a concretização de uma atuação consciente e autônoma da população. Especialmente, no que se refere à definição dos riscos, percebeu-se que tal desrespeito aos direitos sociais básicos pode propiciar a aceitação de riscos socioambientais graves, em razão da dependência econômica de tal comunidade frente ao empreendimento (mesmo que, como no caso concreto, em relação a expectativas futuras). Tem-se, portanto, que um processo legítimo e independente de construção social do risco tem como 
premissa o respeito ao mínimo existencial socioambiental, núcleo do princípio da dignidade da pessoa humana.

\section{Referências}

ACSELRAD, Henri. Ambientalização das lutas sociais - o caso do movimento por justiça ambiental. Estudos Avançados, São Paulo, 2010a.

ACSERLRAD, Henri; MELLO, Cecilia Campello do Amaral; BEZERRA, Gustavo das Neves. O que é Justiça Ambiental. Rio de Janeiro: Garamond, 2009.

ACSELRAD, Henri; HERCULANO, Selene; PÁDUA, José Augusto. Introdução. In: ACSELRAD, Henri; HERCULANO, Selene; PÁDUA, José Augusto (Org.). Justiça Ambiental e Cidadania. Rio de Janeiro: Relume Dumará: Fundação Ford, 2004.

ACSELRAD, Henri. Vulnerabilidade ambiental, processos e relações. In: LEITE, José Rubens Morato; FERREIRA, Heline Sivini; BORATTI, Larissa Verri (Org.). Estado de direito ambiental: tendências. Rio de Janeiro: Forense Universitária, 2010b. p. 95-103.

AYALA, Patryck de Araújo. A proteção jurídica das futuras gerações na sociedade do risco global: o direito ao futuro na ordem constitucional brasileira. In: LEITE, José Rubens Morato; FERREIRA, Heline Sivini; BORATTI, Larissa Verri. Estado de direito ambiental: tendências. Rio de Janeiro: Forense Universitária, 2010. p. 320-358.

BECK, Ulrich. Sociedade de risco: rumo a uma outra modernidade. São Paulo: Editora 34, 2010.

BECK, Ulrich. La sociedad del riesgo global. Trad. Jesús Albores Rey. Madri: Siglo XXI, 2001.

BRASIL. Conama. Resolução 01, de 1986. Coletânea de Legislação de Direito Ambiental, Constituição Federal. São Paulo: Revista dos Tribunais, 2008. p. 589-592. 
BRASIL. Conama. Resolução 237, de 1997. Coletânea de Legislação de Direito Ambiental, Constituição Federal. São Paulo: Revista dos Tribunais, 2008. p. 594-602.

BULLARD, Robert. Enfrentando o racismo ambiental no século XXI. Trad. Carlos Machado de Freitas. In: ACSELRAD, Henri; HERCULANO, Selene; PÁDUA, José Augusto (Org.). Justiça Ambiental e Cidadania. Rio de Janeiro: Relume Dumará: Fundação Ford, 2004. p. 41-68.

CAVEDON, Fernanda de Salles. Conexões entre Direitos Humanos e Direito Ambiental como um contexto mais favorável para a Justiça Ambiental. In: DANTAS, Marcelo Buzaglo; SEGUIN, Elida. (Org.). Direito Ambiental na Atualidade. Rio de Janeiro: Lumen Juris, 2010. p. 161-186.

COSTA, Sérgio. Quase crítica: insuficiências da sociologia da modernização reflexiva. Tempo Social, São Paulo, v. 16, n. 2, nov. 2004. p. 73-100.

CAPRA, Fritjof. O ponto de mutação. São Paulo: Cultrix, 2006.

CANOTILHO, José Joaquim Gomes. Juridicização da ecologia ou ecologização do direito. Revista Jurídica do Urbanismo e do Ambiente, Coimbra, n. 4, p. 69-79, 1995.

CARUSO Jr. Estudos Ambientais e Engenharia Ltda. RIMA - Relatório de Impacto ao Meio Ambiente: OSX ESTALEIRO-SC, 2009.

Disponível em: $<$ http://www.fatma.sc.gov.br/index.php?option=com content\&task=view\&id=97\&Itemid=225> . Acesso em: 13 abr. 2011.

CHRISTMANN, Luiza Landerdahl. Democracia deliberativa e participação popular no licenciamento ambiental do OSX-Estaleiro/SC: desafios e possibilidades. Veredas do Direito, Belo Horizonte, v. 10, n. 20, p. 111-144, 2013.

CHRISTMANN, Luiza Landerdahl. Audiência pública ambiental: um instrumento democrático para a gestão do risco ambiental. Revista Direitos Fundamentais \& Democracia, Curitiba, v. 9, p. 54-90, 2011. 
DI PIETRO, Maria Sylvia Zanella. Direito administrativo. São Paulo: Atlas, 2008.

GIDDENS, Anthony; BECK, Ulrich; LASH, Scott. Modernização reflexiva. Trad. Magda Lopes. São Paulo: UNESP, 1997.

GUIVANT, Julia. A Trajetória das Análises de Risco: da periferia ao centro da teoria social. Revista Brasileira de Informações

Bibliográficas em Ciências Sociais, Rio de Janeiro, n. 46, p. 3-38, 1998. GUIVANT, Julia. A teoria da sociedade de risco de Ulrich Beck: entre o diagnóstico e a profecia. Estudos Sociedade e Cultura, Rio de Janeiro, n. 16, p. 95-112, 2001.

HERMITTE, M. A. Os fundamentos jurídicos da sociedade do risco. Uma análise de U. Beck. In: VARELLA, Marcelo Dias (Org.). Governo dos Riscos. Brasília, DF: Rede Latino-Americana-Européia sobre Governo dos Riscos, 2005. (não paginado)

HANNIGAN, John. Sociologia ambiental. Trad. Annahid Burnett. Petrópolis: Vozes, 2009.

LEFF, Enrique. Racionalidade ambiental: a reapropriação social da natureza. Trad. Luís Carlos Cabral. Rio de Janeiro: Civilização Brasileira, 2006.

MINAYO, Maria Cecília de Souza. O desafio do conhecimento: pesquisa qualitativa em saúde. São Paulo: Hucitec, 2008.

MORIN, Edgar. Os sete saberes necessários à educação do futuro. Trad. Catarina Eleonora F. da Silva e Jeanne Sawaya. São Paulo: Cortez; Brasília: UNESCO, 2001.

OST, François. A natureza à margem da lei: a ecologia à prova do direito. Trad. Joana Chaves. Lisboa: Instituto Piaget, 1995.

PUREZA, José Manuel. O Estatuto do Ambiente na Encruzilhada de Três Rupturas. Oficina n. 102. Oficina do Centro de Estudos Sociais. Coimbra: Centro de Estudos Sociais, 1997. Disponível em: $<$ http://www. ces.uc.pt/publicacoes/oficina/ficheiros/102.pdf>. Acesso em: 19 abr. 2011. 
REDE Brasileira de Justiça Ambiental. Declaração de Princípios da Rede Brasileira de Justiça Ambiental, 2001. Disponível em: <http://www. justicaambiental.org.br/ justicaambiental/pagina.php?id=229>. Acesso em: 10 fev. 2011.

SANTOS, Boaventura de Sousa. Subjetividade, Cidadania e Emancipação. Revista Crítica de Ciências Sociais, Coimbra, n. 32, p. 135-191, 1991.

SARLET, Ingo; FENSTERSEIFER, Tiago. Estado socioambiental e mínimo existencial (ecológico?): algumas aproximações. In: SARLET, Ingo Wolfgang. Estado socioambiental e direitos fundamentais. Porto Alegre: Livraria do Advogado, 2010. p. 11-38.

Rogério Silva Portanova é graduado em Direito pela Pontifícia Universidade Católica do Rio Grande do Sul (1983), possui especialização em Sociologia Política pela Universidade Federal de Santa Catarina (1987), mestrado em Direito pela mesma Universidade (1988), doutorado em Sociologie et Anthropologie du Politique pela Université Paris 8 Vincennes-Saint-Denis (1994) e pós-doutorado pela Universidade Lusíada de Lisboa (2012). Atualmente é professor associado da Universidade Federal de Santa Catarina e Membro de corpo editorial da Sequência (UFSC). Tem experiência na área de Direito, com ênfase em Teoria do Direito. Atuando principalmente nos seguintes temas: ecologia, política.

E-mail: rogerio.portanova@ufsc.br

Endereço profissional: Universidade Federal de Santa Catarina - Centro de Ciências Jurídicas - Campus Universitário - Trindade. CEP: 88040970 Florianópolis, $\mathrm{SC}-$ Brasil.

Luiza Landerdahl Christmann é Mestre em Direito pela Universidade Federal de Santa Catarina. Professora do Centro Universitário Católico de Santa Catarina em Jaraguá do Sul. Professora Conteudista da Especialização em Direito Ambiental da Universidade do Sul de Santa Catarina. Pesquisadora na área de Direito, Meio Ambiente e Ecologia Política. 
E-mail: luizalc.direito@yahoo.com.br

Endereço profissional: Rua dos Imigrantes 500 - Bairro Rau. CEP: 89.254-430. Jaraguá do Sul - SC. 